\title{
Nutritional screening in surgical patients of a teaching hospital from Southern Brazil: the impact of nutritional risk in clinical outcomes
}

\author{
Rastreamento nutricional em pacientes cirúrgicos de um hospital universitário \\ do sul do Brasil: o impacto do risco nutricional em desfechos clínicos
}

\author{
Rosane Scussel Garcia ${ }^{1}$, Léa Regina da Cunha Tavares ${ }^{2}$, Carla Alberici Pastore ${ }^{1}$
}

\begin{abstract}
Objective: To assess the prevalence of nutritional risk in surgical patients of a teaching hospital and its associated factors. Methods: A cross-sectional study with secondary data of surgical ward patients of the Hospital Escola da Universidade Federal de Pelotas, from April to October, 2010. Patients were evaluated up to 36 hours after admission using the Malnutrition Screening Tool. Results: The study included 565 patients, with a mean age of $52.8 \pm 15.6$ years, and the majority (51\%) was female. More than $30 \%$ of the patients presented with an average or high nutritional risk, and $7 \%$ of them were at high risk. Associated with the greater risk were aging, cancer surgery, and mortality. The length of hospital stay showed a linear increase according to nutritional risk. Conclusion: The Malnutrition Screening Tool is a simple and effective tool for nutritional screening that does not require anthropometric measurements. In this study, average or high nutritional risk was prevalent in one third of the sample, and was related to increased mortality, hospital stay, cancer, and aging. Nutritional care outpatients' protocols could be used prior to elective surgery to reduce the nutritional risk of these patients, improving clinical outcomes and reducing length and costs of hospital stay.
\end{abstract}

Keywords: Nutritional therapy; Malnutrition; Surgical procedures

\section{RESUMO}

Objetivo: Avaliar a prevalência de risco nutricional em pacientes cirúrgicos de um hospital universitário e seus fatores associados. Métodos: Estudo transversal com dados secundários de pacientes da ala cirúrgica do Hospital Escola da Universidade Federal de
Pelotas, de abril a outubro de 2010. Os pacientes foram avaliados até 36 horas após a internação, sendo aplicado o Malnutrition Screening Tool. Resultados: Foram incluídos 565 pacientes, com idade média de $52,8 \pm 15,6$ anos, sendo a maioria $(51 \%)$ do gênero feminino. Mais de $30 \%$ dos pacientes apresentaram risco nutricional médio ou alto, sendo cerca de $7 \%$ com alto risco. Estiveram associados ao maior risco nutricional: avanço da idade, cirurgias neoplásicas e mortalidade. 0 tempo de permanência hospitalar mostrou aumento linear de acordo com o risco nutricional. Conclusão: 0 Malnutrition Screening Tool é uma ferramenta simples e efetiva de rastreamento nutricional, dispensando medidas antropométricas. Neste estudo, médio ou alto risco nutricional foi prevalente em um terço da amostra e esteve relacionado com aumento de mortalidade, de permanência hospitalar, câncer e aumento da idade. Protocolos de cuidados nutricionais ambulatoriais prévios a cirurgias eletivas poderiam ser empregados na redução do risco nutricional desses pacientes, melhorando os desfechos clínicos e reduzindo o tempo e os custos da internação.

Descritores: Terapia nutricional; Desnutrição; Procedimentos cirúrgicos

\section{INTRODUCTION}

Intrahospital malnutrition is an important public health problem, since it increases morbidity and mortality of patients who do not present with an adequate nutritional status at hospital admission.

Malnutrition proves to be associated with longer hospital stay ${ }^{(1-3)}$, and higher rates of complications ${ }^{(4)}$ and

Study carried out at Hospital Escola da Fundação de Apoio Universitário, Universidade Federal de Pelotas, Pelotas, RS, Brazil.

${ }^{1}$ Universidade Federal de Pelotas, Pelotas, RS, Brazil.

${ }^{2}$ Hospital Escola da Fundação de Apoio Universitário, Universidade Federal de Pelotas, Pelotas, RS, Brazil.

Corresponding author: Carla Alberici Pastore - Hospital Escola da Universidade Federal de Pelotas - Rua Professor Araújo, 538 - Centro - Zip code: $96020-360$ - Pelotas, RS, Brazil - Phone: (55 53) 3284-4960 Email: pastorecarla@yahoo.com.br

Received on: June 14, 2012 - Accepted on: Apr 2, 2013

Conflict of interest: none.

Financing sources: none. 
mortality ${ }^{(5)}$, also implying higher hospital costs. The cost of hospitalization increases by approximately $68 \%$ in malnourished patients, due to longer hospital stays, greater expenses with medications to treat complications (especially infectious), as well as greater costs of nutritional support to treat the established malnutrition $^{(6)}$.

A large study called the Inquérito Brasileiro de Nutrição (IBRANUTRI, acronym in Portuguese) [The Brazilian Nutrition Survey] that sought to delineate the nutritional profile of inpatients in various hospitals all over Brazil, revealed that well-nourished patients stay, in average, six days at hospital, while those moderately malnourished have an average stay of 9 days and the severely malnourished individuals, an average of 13 days. Increased hospital stay corresponds to increased risk of infections and complications, as well as increased costs, since besides prolonged occupation of the bed, there is an increase in costs with medications and treatments necessary to care for these complications ${ }^{(2)}$. The same study demonstrated that about $48 \%$ of the hospitalized population in Brazil has some degree of malnutrition $^{(2)}$.

Even in developed countries, intrahospital rates of malnutrition are high, such as in England (20\%) ${ }^{(3)}$ and in Australia $(36 \%)^{(5)}$. In developing countries, such as in Latin American, the prevalence of malnutrition in hospitalized patients is about $50 \%{ }^{(7,8)}$.

Despite being prevalent, malnutrition is frequently not recognized and is undertreated in clinical practice ${ }^{(9)}$. Some studies showed that less than $50 \%$ of malnourished patients received appropriate nutritional treatment since their nutritional status was not effectively recognized ${ }^{(10,11)}$.

In order to improve the approach to and identification of patients with nutritional risk, i.e., those who are more likely to have malnutrition during their hospital stay, the routine use of simple screening procedures is recommended ${ }^{(11)}$.

Nutritional screening identifies individuals who are malnourished or at risk of developing malnutrition, and those who can benefit from specific nutritional support. For this, it is necessary to apply a simple, effective, and validated tool for hospital use ${ }^{(12)}$.

Several tools were developed for nutritional screening, such as the Malnutrition Universal Screening Tool (MUST) ${ }^{(13)}$, Imperial Nutritional Screening System (INSYST) $^{(14)}$, Short Nutritional Assessment Questionnaire (SNAQ) $^{(15)}$, Mini Nutritional Assessment (MNA) ${ }^{(16)}$ - for elderly patients -, the Avaliação Subjetiva Global (ASG) [Global Subjective Evaluation] ${ }^{(17)}$ - which can be used either as a screening tool or for assessing nutritional status -, and the Malnutrition Screening Tool (MST) ${ }^{(12)}$.

The MST is a quick, simple, validated, and effective tool, and it is plausibly applied to the large volume of patients who are daily admitted to hospitals ${ }^{(12)}$. It is a sensitive screening method for detecting patients at nutritional risk, and takes 3 to 5 minutes to be completed and interpreted ${ }^{(18)}$.

The MST has the ease of not requiring the patient's weight and height, data that is not always present during the first hours of hospitalization, often due to the impossibility of moving the patient. Focusing on subjective data, such as history of weight loss and loss of appetite, and changes in the patient's food ingestion, this tool identifies patients at risk, and shows a good correlation with other methods that are lengthier, more complex, and that need anthropometric data of the individual, such as weight and height ${ }^{(18)}$.

Three studies carried out at the same hospital in London (United Kingdom), during the years 1998, 2000 and 2003, showed that from the time when the hospital adopted the nutritional screening process, the prevalence of malnutrition was significantly reduced (from $23.5 \%$ in 1998 , to $20.4 \%$ in 2000 , and to $19.1 \%$ in 2003). This reduction is attributed to screening, since it allows identification and treatment of patients with nutritional risk before they, in fact, become malnourished ${ }^{(19)}$.

\section{OBJECTIVE}

To evaluate the prevalence of nutritional risk in hospitalized patients and the length of stay required by such patients, according to their category of nutritional risk at the time of admission.

\section{METHODS}

This is a cross-sectional study conducted in patients hospitalized in the surgical ward of the Hospital Escola da Universidade Federal de Pelotas (RS), from April to October, 2010, using secondary data taken from admission medical charts of these patients (history taken and screening already routinely performed by the hospital's Nutrition Service). This hospital serves exclusively through the Public Brazilian Unified Healthcare System (SUS).

Excluded from the study were patients aged under 18 years or those whose information, for whatever reason, could not be reliably collected.

The patients admitted were evaluated by the nutrition team up to 36 hours after admission. Nutrition 
students, under the supervision of hospital dieticians, applied the questionnaires and the routine assessments for the nutritional procedures of the service.

One of the standardized questionnaires at the service is the $\operatorname{MST}^{(12)}$, the tool chosen by the service for nutritional screening due to quickness and ease of completion, with no need for anthropometric data at the beginning of the hospital stay, and that can be applied by any duly trained healthcare professional. The MST covers three issues: if there was recent non-intentional weight loss; if yes, how great the loss was; and if the patient has been eating poorly due to less appetite. These questions generate a numerical score, in which $0-1$ point indicate a low risk and a need for reevaluation (performed every 7 days at the service, if the patient is hospitalized), 2-3 points indicate an average risk, and 4-5 points indicate high risk; patients at average or high risk undergo a detailed history taking, nutritional evaluation, and diet therapy.

After collecting data from the medical charts (gender, age, type of surgery, and MST result) and outcome for the patient (discharged, transferred, or death), the questionnaires were entered into a Microsoft Excel ${ }^{\circledR}$ databank, with double entry and checking for consistency. The convenience sample was collected for 7 months, reaching 565 patients. Statistical analyses were made using the Stata $9.1^{\circledR}$ package, and values of $\mathrm{p}<0.05$ were accepted as significant.

This survey did not involve exposure of the patient to any type of risk to his/her health or personal exposure. The data collected were secondary, thus exempting them from signing the participants' Informed Consent Form.

This project was approved by the Research Ethics Committee responsible for the Hospital Escola da Universidade Federal de Pelotas, as per Official Notice \# 45/10, of October 4, 2010.

\section{RESULTS}

The study included 565 patients, most of them $(51 \%)$ females. The mean age of the sample was 52.8 years ( \pm 15.6 years), varying from 18 to 91 years. Most patients had as outcome hospital discharge (96.6\%). The complete description of the sample may be found on table 1.

The mean time of hospitalization was 7.4 days ( \pm 10.0 days), with a maximum of 89 days. This variable did not show a normal distribution (Skewness/Kurtosis normality test $-\mathrm{p}=0.000$ ), so that, in terms of results, this variable is presented in the form of median and interquartile interval (IQI).
Table 1. Description of sample of surgical patients at the Hospital Escola da Universidade Federal de Pelotas, RS, 2010

\begin{tabular}{lcc}
\hline Variable & $\mathbf{n}$ & $\%$ \\
\hline Gender & & \\
$\quad$ Male & 275 & 48.7 \\
$\quad$ Female & 290 & 51.3 \\
Age & & \\
$\quad<45$ years & 166 & 29.4 \\
$\quad 45-60$ years & 194 & 34.3 \\
$>60$ years & 205 & 36.3 \\
Outcome & & \\
$\quad$ Discharge & 546 & 96.6 \\
Death & 11 & 2.0 \\
$\quad$ Transfer & 8 & 1.4 \\
\hline Total & 565 & 100 \\
\hline
\end{tabular}

The operations performed were of various types, most of them related to neoplasms (38.6\%), and followed by biliary lithiasis surgery, as is shown on table 2 .

Table 2. Surgical diagnoses in the sample of patients at the Hospital Escola da Universidade Federal de Pelotas, RS, 2010

\begin{tabular}{lll}
\hline Surgery & $\mathbf{n}$ & $\%$ \\
\hline Neoplasm head/neck & 24 & 4.2 \\
Neoplasm - respiratory system & 50 & 8.8 \\
Neoplasm - gastrointestinal tract & 77 & 13.6 \\
Other neoplasms* & 67 & 11.9 \\
Biliary lithiasis (cholecystectomy / videocholecystectomy) & 137 & 24.3 \\
Herniorraphy & 78 & 13.8 \\
Other surgeries** & 132 & 23.4 \\
\hline Total & 565 & 100 \\
\hline * Other neoplasms include neoplasm of genitourinary tract, prostate, soft tissues, lower and upper limbs; \\
** Other surgeries include hemorrhoidectomy, thyroidectomy, non-oncological surgeries of the urinary, digestive and \\
respiratory tracts; and new surgeries due to non-oncological postoperative complications.
\end{tabular}

The results obtained from the application of the MST show that most patients did not present with weight loss prior to admission (57\%) or any change in food intake $(74 \%)$. The nutritional screening tool showed that $33.1 \%$ of the patients in the surgical ward of the hospital presented with an average or high nutritional risk, and almost $7 \%$ were at high risk (Table 3). Among the patients, $18 \%$ had lost between 1 and $5 \mathrm{~kg}$, and almost $11 \%$ had lost more than $10 \mathrm{~kg}$ relative to their habitual weight.

The nutritional risk was not significantly different between genders $\left(p>0.05, \chi^{2}\right.$ test $)$, but there were 
Table 3. Results of applying the Malnutrition Screening Tool to the sample of surgical patients at the Hospital Escola da Universidade Federal de Pelotas, RS, 2010

\begin{tabular}{lcc}
\hline MST variable & $\mathbf{n}$ & $\%$ \\
\hline Recent weight loss & 321 & 56.8 \\
No & 15 & 2.7 \\
Does not know & 102 & 18.1 \\
1-5kg & 59 & 10.4 \\
6-10kg & 33 & 5.8 \\
11-15kg & 27 & 4.8 \\
$>15 \mathrm{~kg}$ & 8 & 1.4 \\
Yes, do not know how much & & \\
Decreased habitual diet & 416 & 73.6 \\
No & 149 & 26.4 \\
Yes & & \\
Nutritional risk classification & 378 & 66.9 \\
Low risk (0-1 point) & 148 & 26.2 \\
Medium risk (2-3 points) & 39 & 6.9 \\
High risk (4-5 points) & 565 & 100 \\
\hline Total & & \\
\hline
\end{tabular}

MST: Malnutrition Screening Tool.

differences related to age, surgical diagnosis, outcome of patients (Table 4), and length of hospital stay (Figure 1).

As to age, the higher the age group of patients, the greater the prevalence of high nutritional risk, reaching $54 \%$ in patients over 60 years of age $\left(\mathrm{p}<0.001, \chi^{2}\right.$ test $)$. The surgical diagnosis of neoplasm was related to a greater nutritional risk when compared to the other

Table 4. Factors associated to nutritional risk in a sample of surgical patients at the Hospital Escola da Universidade Federal de Pelotas, RS, 2010

\begin{tabular}{|c|c|c|c|c|c|c|c|}
\hline \multirow{3}{*}{$\begin{array}{l}\text { Associated } \\
\text { variable }\end{array}$} & \multicolumn{6}{|c|}{ Nutritional risk } & \multirow{3}{*}{ p value ${ }^{*}$} \\
\hline & \multicolumn{2}{|c|}{ Low } & \multicolumn{2}{|c|}{ Medium } & \multicolumn{2}{|c|}{ High } & \\
\hline & $\mathbf{n}$ & $\%$ & $\mathrm{n}$ & $\%$ & $\mathbf{n}$ & $\%$ & \\
\hline Age (years) & & & & & & & $<0.001$ \\
\hline$<45$ & 129 & 34.1 & 34 & 23.0 & 3 & 7.7 & \\
\hline $45-60$ & 134 & 35.5 & 45 & 30.4 & 15 & 38.5 & \\
\hline$>60$ & 115 & 30.4 & 69 & 46.6 & 21 & 53.8 & \\
\hline Diagnosis & & & & & & & $<0.001$ \\
\hline Neoplasm & 116 & 30.7 & 79 & 53.4 & 23 & 59.0 & \\
\hline Others & 262 & 69.3 & 69 & 46.6 & 16 & 41.0 & \\
\hline Outcome & & & & & & & $<0.001$ \\
\hline Discharge & 376 & 99.5 & 138 & 93.2 & 32 & 82.1 & \\
\hline Transfer & 2 & 0.5 & 4 & 2.7 & 2 & 5.1 & \\
\hline Death & 0 & 0.0 & 6 & 4.1 & 5 & 12.8 & \\
\hline Total & 378 & 100 & 148 & 100 & 39 & 100 & \\
\hline
\end{tabular}

${ }^{*} \chi^{2}$ test.

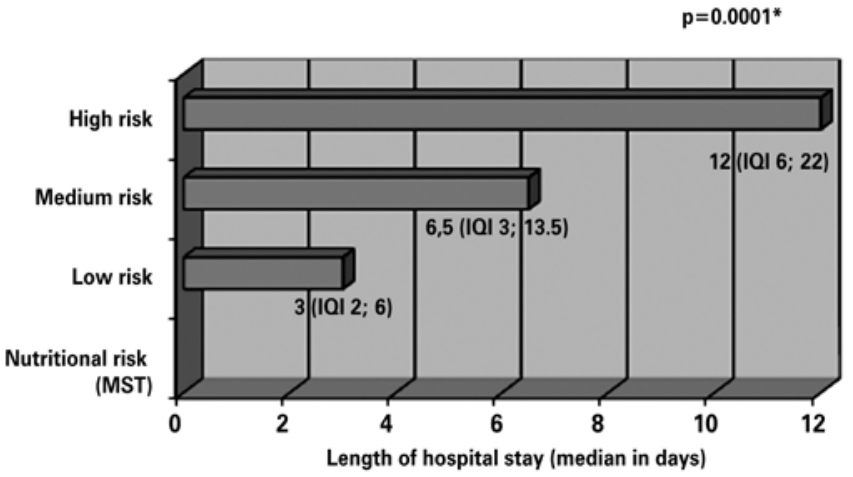

MST: Malnutrition Screening Tool.

Figure 1. Relation between nutritional risk and length of hospital stay in a sample of surgical patients at the Hospital Escola da Universidade Federal de Pelotas, RS, 2010

types of surgery; cancer patients had a high nutritional risk $(59 \%)$ versus those with other diagnoses (41\%). Only $31 \%$ of the oncology patients showed a low nutritional risk, while in diagnoses different from cancer, this value increased to $69 \%$ ( $\mathrm{p}<0.001, \chi^{2}$ test).

When the hospital outcome of patients is observed, the rise in mortality rates according to increased nutritional risk is remarkable: zero per cent in patients with a low risk, to $4 \%$ in those with a medium risk, and reaching the level of $13 \%$ in patients with a high nutritional risk $\left(\mathrm{p}<0.001, \chi^{2}\right.$ test $)$. Having a high nutritional risk brought with it a probability three times higher of death relative to patients with a medium nutritional risk (prevalence ratio of 3.16, with a $95 \%$ confidence interval $(95 \% \mathrm{CI})$ of $1.02-9.82 ; \mathrm{p}=0.04)$.

Time of hospital stay showed a linear increase according to the increased nutritional risk. The length of hospital stay of high-nutritional-risk patients was four-fold longer than that of low-risk patients, achieving a median of 12 days, while patients with a medium risk had a median stay of 6.5 days $(\mathrm{p}<0.001$, Kruskal-Wallis test).

\section{DISCUSSION}

Recurrent failure in recognizing and treating malnutrition, especially where it is very frequent (hospital), is an obstacle to healthcare. Under these conditions, the routine use of a simple screening, capable of identifying the patient's nutritional risk, is recommendable ${ }^{(11)}$.

Nutritional screening benefits the individuals who are malnourished or at a risk for malnutrition who may be benefited from nutritional support ${ }^{(12)}$.

In the present study, the screening done with the MST ${ }^{(12)}$ resulted in one third of the patients with nutritional risk, in which the majority of these were 
identified with medium risk. Many studies measured the prevalence of nutritional risk in hospitalized patients, using diverse tools for this. The MST, however, has not been frequently used in the studies published, since most have used the ASG as a screening tool upon hospital admission ${ }^{(17)}$.

Studies using ASG reported a prevalence of malnutrition/nutritional risk in inpatients (clinical and surgical) between 36 and $50 \%{ }^{(5,7,8)}$, in different countries of the world. A study using anthropometrics and body mass index to define malnutrition found a prevalence of $20 \%$ in a general hospital population ${ }^{(3)}$. Lamb et al., using the MST nutritional screening tool ${ }^{(13)}$, found $44 \%$ of nutritional risk - in that, $13.7 \%$ patients were at a high risk. In a literature review on nutritional screening, Elia et al. ${ }^{(11)}$ reported a prevalence of hospital nutritional risk between 10 and $60 \%$, depending on the tool used, and the present study corroborates the data of that review.

In 2008, Vidal et al..$^{(1)}$ published an article in which, using ASG as the tool, they found $40.2 \%$ of prevalence of malnutrition among surgical and clinical patients at a Spanish hospital, showing that there was no difference in terms of prevalence between the two types of patients. This same study pointed out that $54 \%$ of the surgical patients had decreased their habitual food intake, while in the present study only about one fourth of the patients reported this reduction.

In the study entitled IBRANUTRI ${ }^{(2)}$, with hospitalized patients in general (not only surgical) evaluated by ASG, Waitzberg et al. showed a malnutrition prevalence of $48.1 \%$, in which $12.5 \%$ were severe cases of malnutrition. It is important to point out that IBRANUTRI assessed patients in many hospitals from north to south of the extensive Brazilian territory, and found large regional discrepancies. In the north of the country, a region with the lowest income per capita, the prevalence of malnutrition reached $78.8 \%$. In the south of the country, the prevalence was $38.9 \%$, close to the prevalence reported in the present study, which was conducted at a hospital in the extreme southern region of Brazil. Despite the use of distinct tools, the regional results are similar.

The increase in patient age was significantly associated with the higher nutritional risk in the sample studied here. Also in the studies by Waitzberg et al.(2), Middleton et al. ${ }^{(5)}$, Correia et al. ${ }^{(7)}$, Wyszynski et al..$^{(8)}$, and Lamb et al. ${ }^{(10)}$, even using distinct screening tools, the increase in age was related to the increase in nutritional risk/malnutrition, primarily for those over 60 years of age.

Diagnosis of the patient was also associated with the nutritional risk in the present study. Finding similarity with several other studies, the diagnosis of cancer was related to a greater nutritional risk $^{(1,2,7,8)}$. In the IBRANUTRI $^{(2)}$ study, patients with cancer presented with a risk $55 \%$ higher of being malnourished than did non-cancer patients.

In the sample studied, mortality was linearly greater as the nutritional risk increased. In a study carried out in Sydney, Australia, Middleton et al. ${ }^{(5)}$ described a 12-month mortality after evaluation with ASG almost three-fold higher among malnourished patients relative to those who were well nourished. Regarding deaths during hospitalization, $2.7 \%$ of the malnourished patients died, while only $1 \%$ of the well-nourished patients had this outcome.

In the present study, the increase in nutritional risk was significantly associated with length of hospital stay $(\mathrm{p}<0.001)$. Similar findings were described in other studies $^{(1,2,5,7)}$. In Brazil, the IBRANUTRI ${ }^{(2)}$ study reports a median hospital stay of 6 days for well-nourished patients, 9 days for moderately malnourished/with risk of malnutrition, and 13 days for severely malnourished patients. In a multicenter study conducted in several Latin American countries, Correia et al. ${ }^{(7)}$ found a relative risk of 3.00 (95\% CI: 2.61-3.45) of malnourished patients having a hospital stay of more than 14 days relative to the well-nourished.

MST is a simple, quick, valid, and safe tool that can be used to identify patients with nutritional risk ${ }^{(12)}$. It has the ease of not using anthropometric data for screening, which makes it feasible during the first hours of hospital admission, even if the patient cannot move for measuring weight and height.

In their article, Edington et al. ${ }^{(3)}$ reported a loss of $15.9 \%$ of their eligible population (1611 patients), since 256 individuals could not be weighed. The MST, with questions about recent weight loss and loss of appetite, can be applied without anthropometric measurements, and has convergent and predictive validity relative to other nutritional screening methods ${ }^{(12)}$.

\section{CONCLUSION}

The MST proved to be a simple and effective tool for nutritional screening with the advantage of exempting the patient from anthropometric measurements, not always available during the first hours of hospital admission.

In this study, greater nutritional risk was related to an increase in mortality, length of hospital stay, diagnosis of cancer, and increased age.

There is substantial evidence that treatable malnutrition is under-recognized and undertreated. There are formal recommendations from societies of nutritional therapy 
from around the world and Brazil that patients admitted to hospitals be screened and that the screening process be repeated periodically. In this way, patients that can benefit from nutritional support will be identified in a correct and early manner.

\section{REFERENCES}

1. Vidal A, Iglesias MJ, Pertega S, Ayúcar A, Vidal O. [Prevalence of malnutrition in medical and surgical wards of a university hospital]. Nutr Hosp. 2008; 23(3):263-7. Spanish.

2. Waitzberg DL, Caiaffa WT, Correia MI. Hospital malnutrition: the Brazilian national survey (IBRANUTRI): a study of 4000 patients. Nutrition. 2001;17(7-8): 573-80.

3. Edington J, Boorman J, Durrant ER, Perkins A, Giffin CV, James R, et al. Prevalence of malnutrition on admission to four hospitals in England. The Malnutrition Prevalence Group. Clin Nutr. 2000;19(3):191-5.

4. Naber TH, Schermer T, de Bree A, Nusteling K, Eggink L, Kruimel JW, et al. Prevalence of malnutrition in nonsurgical hospitalized patients and its association with disease complications. Am J Clin Nutr. 1997;66(5):1232-9.

5. Middleton MH, Nazarenko G, Nivison-Smith I, Smerdely P. Prevalence of malnutrition and 12-month incidence of mortality in two Sydney teaching hospitals. Int Med J. 2001;31(8):455-61.

6. Pérez de la Cruz A, Lobo Támer G, Orduña Espinosa R, Mellado Pastor C, Aguayo de Hoyos E, Ruiz López MD. [Malnutrition in hospitalized patients: prevalence and economic impact]. Med Clin. 2004;123(6):201-6. Spanish.

7. Correia MI, Campos AC; ELAN Cooperative Study. Prevalence of hospital malnutrition in Latin America: the multicenter ELAN study. Nutrition. 2003; 19(10):823-5.

8. Wyszynski DF, Perman M, Crivelli A. Prevalence of hospital malnutrition in Argentina: preliminary results of a population-based study. Nutrition. 2003;19(2):115-9.
9. Meijers JM, Halfens RJ, van Bokhorst-de van der Schueren MA, Dassen T, Schols JM. Malnutrition in Dutch health care: prevalence, prevention, treatment, and quality indicators. Nutrition. 2009;25(5):512-9.

10. Lamb CA, Parr J, Lamb El, Warren MD. Adult malnutrition screening, prevalence and management in a United Kingdom hospital: cross-sectional study. Br J Nutr. 2009;102(4):571-5.

11. Elia M, Zellipour L, Stratton RJ. To screen or not to screen for adult malnutrition? Clin Nutr. 2005;24(6):867-84.

12. Ferguson M, Capra S, Bauer J, Banks M. Development of a valid and reliable malnutrition screening tool for adult acute hospital patients. Nutrition. 1999; 15(6):458-64.

13. Karsegard VL, Ferlay O, Maisonneuve N, Kyle UG, Dupertuis YM, Genton L, et al. [Simplified malnutrition screening tool: Malnutrition Universal Screening Tool (MUST)]. Rev Med Suisse Romande. 2004;124(10):601-5. French.

14. Tamman JD, Gardner L, Hickson M. Validity, reliability and acceptability of the Imperial Nutritional Screening System (INSYST): a tool that does not require the body mass index. J Hum Nutr Diet. 2009;22(6):536-44.

15. Kruizenga HM, Seidell JC, de Vet HC, Wierdsma NJ, van Bokhort-de van der Schueren MA. Development and validation of a hospital screening tool for malnutrition: the short nutritional assessment questionnaire (SNAQ). Clin Nutr. 2005;24(1):75-82.

16. Guigoz $Y$, Vellas BJ. Malnutrition in the elderly: the Mini Nutritional Assessment (MNA). Ther Umsch. 1997;54(6):345-50.

17. Detsky AS, McLaughlin JR, Baker JP, Johnston N, Whittaker S, Mendelson $R A$, et al. What is subjective global assessment of nutritional status? J Parenter Enteral Nutr. 1987;11(1):8-13.

18. Stratton RJ, Hackston A, Longmore D, Dixon R, Price S, Stroud M, et al Malnutrition in hospital outpatients and inpatients: prevalence, concurrent validity and ease of use of the 'malnutrition universal screening tool' ('MUST') for adults. Br J Nutr. 2004;92(5):799-808.

19. O'Flynn J, Peake H, Hickson M, Foster D, Frost G. The prevalence of malnutrition in hospitals can be reduced: results from three consecutive cross-sectional studies. Clin Nutr. 2005;24(6):1078-88. 